\title{
Cuidado com os poetas! Literatura e periferia da cidade de São Paulo
}

Tennina, Lucía (2017).

Porto Alegre, Zouk, 316 pp.

ISBN 9788580490558.

\section{(4) Aline Teixeira da Silva Lima}

Universidade de Brasilia, Brasil

É sabido que, ao associar literatura com o adjetivo "marginal", estamos classificando "as obras literárias produzidas e vinculadas à margem do corredor editorial, que não pertencem ou que se opõem aos cânones estabelecidos, que são de autoria de escritores originários de grupos sociais marginalizados, ou ainda, que tematizam o que é peculiar aos sujeitos e espaços tidos como marginais" (Nascimento, 2009: 20s.). Nessa estética literária, é perceptível, dentre outras características próprias, o cunho social e político, haja vista que esses escritores, por meio da literatura, se posicionam, denunciam os problemas do meio onde estão inseridos e firmam suas identidades, resgatando também suas memórias individuais ou coletivas.

A mais recente obra de Lucía Tennina, intitulada Cuidado com os poetas! Literatura e periferia da cidade de São Paulo, publicada pela editora Zouk (2017), é um estudo aprofundado sobre essa literatura, problematizando as questões em torno do campo literário a partir das produções da literatura marginal da periferia paulista. Sua motivação para com esse corpus de estudo, assim como a trajetória percorrida até chegar à fatura do presente livro, é contada em primeira pessoa na introdução do mesmo, possibilitando uma maior aproximação do leitor para com o objeto narrado. É notável a importância do trabalho de campo antropológico' realizado pela autora, tendo em vista que muitos dos textos analisados

\footnotetext{
1 Tal pesquisa rendeu um rico material visual. Parte desse conteúdo ilustra o final de cada capítulo, dialogando com o mesmo. Além disso, ao final da obra o leitor encontrará um resumo bibliográfico de cada autor citado que faz parte da literatura marginal da periferia. Esse anexo é imprescindível para uma melhor compreensão do livro como um todo, principalmente para aqueles que ainda não estão familiarizados com os poetas dos saraus da periferia de São Paulo.
}

não têm circulação fora do circuito dos saraus (o que é um diferencial deste livro, pois a grande parte das bibliografias dedicadas a essa temática traz como corpus apenas textos dos autores mais conhecidos na área). A pesquisadora aproveita-se desse fato para criticar o cenário hegemônico do campo literário brasileiro, visto que este foi construído e edificado tendo como base obras produzidas por homens, heterossexuais, brancos e economicamente bem posicionados e que, para manter essa homogeneização, nega valor literário a determinadas produções, em benefício de outras, reafirmando suas identidades e excluindo, assim, as diferenças.

Por essa razão, a teórica destaca que há uma tensão quando esses grupos marginalizados se autorrepresentam, isto é, quando deixam de ser objeto da fala do outro para se tornar sujeito da sua própria fala, pois de acordo com Regina Dalcastagnè,

$$
\begin{aligned}
& \text { ooutro (mulheres, pobres, negros, trabalhadores) } \\
& \text { está, em geral, ausente; quando incluído nessas } \\
& \text { narrativas, costuma aparecer em posição } \\
& \text { secundária, sem voz e, muitas vezes, marcado } \\
& \text { por estereótipos. Daí a tensão presente em } \\
& \text { textos de escritores e escritoras provenientes } \\
& \text { de outros segmentos sociais, que têm de se } \\
& \text { contrapor a essas representações já fixadas na } \\
& \text { tradição literária e, ao mesmo tempo, reafirmar } \\
& \text { a legitimidade de sua própria construção } \\
& \text { (Dalcastagnè, 2007: 18). }
\end{aligned}
$$

E a partir de teóricos como Pierre Bourdieu, Josefina Ludmer, Flora Süssekind e Regina Dalcastagnè, Tennina questiona e problematiza o conceito de campo literário, abrindo caminho para o primeiro 
capítulo, em que se constata que esse termo adquire ainda maior complexidade quando se trata de "literatura marginal da periferia". A autora opta por usar tal expressão ao longo do livro por acreditar que a mesma dá conta da marginalidade dessas produções no campo literário e de sua relação com um território e uma origem social determinada.

O primeiro capítulo, Os saraus de poesia da periferia de São Paulo: posicionamentos de sujeitos através da literatura, descreve a realização do Sarau da Cooperifa em São Paulo, o qual acontece, desde 2001, todas as quartas-feiras na esquina do bar do Zé Batidão, no bairro de Piraporinha, na Zona Sul de São Paulo. É sempre o poeta Sérgio Vaz $^{2}$ quem inicia o Sarau com uma mensagem de boas-vindas. Vaz é mineiro, porém é morador de São Paulo desde os cinco anos de idade. Há 20 anos reside no bairro Pirajussara, no Município de Taboão da Serra, periferia paulista. Sérgio Vaz se considera pardo, em suas palavras, com "cor de chão de terra que a gente pisa" (Tennina, 2006: 156) e não nega sua origem africana, já que sua avó materna era negra. 0 mesmo não tem formação universitária e se julga um poeta marginal:

Eu me identifico com o termo literatura marginal, eu gosto. Acho que eu tô à margem também, eu não tenho editora, eu tô à margem do processo, eu tô à margem da mídia, eu tô à margem acadêmica. Eu sou marginal, não por opção, né. Eu tô à margem da distribuidora de livro, do ranking da [revista] Veja, à margem da Fnac. Então eu sou marginal dentro desse sentido, né. Eu acho que eu me também defino um pouco como literatura marginal, né, porque eu faço parte dessa marginalidade imposta às pessoas que querem escrever, que não têm títulos acadêmicos, não têm dinheiro pra editar e que às vezes podem morrer com vontade de escrever um livro, podem morrer com quinhentos poemas sem nunca ter editado um livro, podem morrer Zé sem nunca ter sido um Zé poeta (Tennina, 2006: 181).

2 Vale ressaltar que Sérgio Vaz possui uma equipe que o ajuda na organização do Sarau.
Ao detalhar a dinâmica do Sarau da Cooperifa, a pesquisadora consegue que o leitor visualize o mesmo, quase que transcendendo-o até aquele espaço, e o instiga a querer visitá-lo pessoalmente. As falas transcritas de Sérgio Vaz, extraídas de uma entrevista pessoal feita pela própria autora e publicada no livro Polifonias marginais (2006), que estão mescladas ao texto, embasam e ilustram as afirmações de Tennina, a qual salienta que o Sarau da Cooperifa tem uma preocupação em ressaltar o seu caráter literário como evento, o qual não é baseado em lazer, mas sim em um projeto poético bem estruturado, em que seus participantes têm a oportunidade de fazer sua declamação e, ao mesmo tempo, serem (auto)identificados como poetas, legitimando, desta maneira, seus posicionamentos de sujeitos. Além disso, cada poeta é saudado e aplaudido indistintamente, recebendo, assim, o mesmo reconhecimento, porque nos saraus o juízo estético não tem a primazia.

Tennina afirma que a literatura pensada a partir dessa perspectiva é um facilitador, pois ao valorizarse o poeta em si há uma consequente construção da persona ligada a um eu, o qual tem consciência de si mesmo e reconhece o seu valor, o qual é expressado por meio da autoestima, do respeito e até mesmo da honra, já que se desenvolve um sentimento de pertencimento daquele espaço, a periferia. Assim, "os saraus funcionam (...) como um artefato cultural influente na potencialidade de uma vida na periferia" (Tennina, 2017: 56).

A teórica também chama a atenção para a diversidade das identidades representadas nos saraus, o que vai de encontro ao pensamento de Stuart Hall (2006), para quem o sujeito pós-moderno, que antes viveu possuindo uma identidade unificada e estável, hoje está se fragmentando e agora seu composto não é de apenas uma identidade, mas de várias. A autora observou que "por traz da ideia de periférico, esconde-se uma variedade de posições de sujeitos que também aparecem representadas no sarau (...). Entre estas, destacam-se as condições do negro periférico e do nordestino-periférico" (Tennina, 2017: 59). Assim, tal sujeito não se restringe apenas à identidade de poeta, esse se apresenta de 
maneira plural, tendo em vista que este é também marginal e, comumente, expressa sua origem, seja ela negra e/ou nordestina.

É importante ressaltar que não é apenas o trabalho em torno da persona, realizado pelos saraus, já explicitado anteriormente, que possibilita o "falar com autoridade", haja vista que "há uma clara valorização da tradição da voz diante da tradição letra$\mathrm{da}$, e isso não somente como marca de estilo, mas também como marca identitária" (Tennina, 2017: 91). Dessa forma, os códigos da linguagem para os saraus exercem um papel fundamental, questionando a associação da poesia e da literatura com o pensamento letrado e exclusivo. Ainda sobre a linguagem, é importante destacar neste capítulo o tópico sobre a Semana de Arte Moderna da Periferia, em 2007. Tennina explica esse movimento como um diálogo que a literatura marginal dos saraus trava com a literatura canônica, que se deu por meio dos mecanismos de apropriação da ideia do movimento de 1922, do esvaziamento daquele conteúdo de "alta cultura" e da atualização no tempo e espaço periféricos. Fica claro, portanto, que o trabalho voltado para a palavra escrita e para a palavra em ato, em função da ideia de persona (cidadão e linguagem), evidencia o quão complexo é a noção de literatura sustentada nos saraus de poesia.

O capítulo 2, Saraus de poesia no plural: deslocamentos e negociações, estuda a conexão que os saraus estabelecem uns com outros, formando um verdadeiro circuito de circulação da literatura marginal/periférica. Os saraus possuem "seus próprios círculos de venda, seu próprio corpus, suas próprias editoras, seu próprio habitus, seu próprio estilo, sua própria genealogia e repertório, em síntese, seus próprios mecanismos de produção de valor literário, tanto técnicos como simbólicos" (Tennina, 2017: 39). Além disso, eles possuem seu próprio sistema literário. A noção desse sistema, desenvolvido e aplicado por Antonio Candido (1997), para explicar o processo de formação da literatura brasileira, continua atual e contribui para a compreensão da organização e constituição da literatura marginal da periferia a partir de sua tríade independente de autor-obra-público.
Tennina destaca que além dos saraus se constituírem como um circuito, eles também se articulam como cena e movimento. $O$ primeiro se dá por apresentarem uma preocupação comum ligada à ressignificação de uma ideia de periferia, a qual os poetas cultivam e exibem nos textos declamados e em suas performances. E o segundo, pelo fato de existir uma clara intenção e engajamento, dos sujeitos que participam dos saraus, em reivindicar para si o direito de acesso a bens culturais e a constatação do valor literário de suas produções, implicando em mudanças de paradigmas relacionados à representação de tais grupos e seu local de fala, além de buscarem o reconhecimento do seu lugar no campo literário brasileiro. Essa demanda é autenticada por Candido, o qual afirma que

a distinção entre literatura popular e literatura erudita não deve servir para justificar e manter uma separação iníqua, como se do ponto de vista cultural a sociedade fosse dividida em esferas incomunicáveis, dando lugar a dois tipos incomunicáveis de fruidores. Uma sociedade justa pressupõe o respeito dos direitos humanos, e a fruição da arte e da literatura em todas as modalidades e em todos os níveis é um direito inalienável (Candido, 2011: 193).

Tais conceitos são ricamente ilustrados com poesias já declamadas em saraus da periferia. Contudo, a autora esclarece que, apesar dos elementos partilhados (circuito, cena e movimento), os saraus da periferia não são homogêneos. Para demonstrar tal afirmação, Tennina expõe e compara a dinâmica de saraus específicos, apontando para suas características particulares, atestando, consequentemente, a relevância do seu trabalho de campo antropológico, ou seja, do contato físico com os espaços e os atores do movimento.

O alijamento da produção literária de autoria feminina do campo literário não é um fenômeno recente, por essa razão o capítulo 3, As poetas da periferia: imaginários, coletivos, produções e encenações, é uma grande contribuição deste livro para a literatura de autoria feminina, principalmente a de autoria negra feminina. Na literatura, de maneira geral, a voz das 
mulheres é, muitas vezes, silenciada e/ou sobreposta por vozes que falam por ela. Na literatura marginal da periferia não é diferente, pois Tennina afırma que essa dominação masculina e submissão feminina "pode ser percebida em grande parte dos escritores da literatura marginal" (Tennina, 2017: 179), porém, a teórica reconhece que existem falas plurais na periferia, ou seja, a mulher está presente neste espaço, e não mais de maneira condescendente com a posição a elas relegada, a de segundo plano, em relação ao homem, pois vem reivindicando seu espaço literário. Percebe-se que para Tennina, assim como para Pierre Bourdieu (2014) e Elaine Showalter, essas relações de gênero são, na verdade, relações de poder, tendo em vista que

$$
\begin{aligned}
& \text { gênero não é apenas uma questão de diferença, } \\
& \text { o que presume que os sexos sejam distintos e } \\
& \text { iguais; mas de poder, já que observando a história } \\
& \text { das relações de gênero, encontramos assimetria } \\
& \text { sexual, desigualdade e dominação masculina em } \\
& \text { qualquer sociedade (Showalter, 1989: 4). }
\end{aligned}
$$

E como exemplos da presença feminina na literatura marginal de periferia, a pesquisadora traz análises detalhadas de textos das poetas Dina Di, considerada a primeira mulher a alcançar o protagonismo na cena do rap brasileiro, Raquel Almeida, Elizandra Souza e Dinha. Vale destacar que neste capítulo há um subtópico destinado apenas à escritora Carolina Maria de Jesus, a qual foi uma precursora da literatura feminina, negra e periférica, legitimando, portanto, os textos das autoras que a sucederam.

Tais produções torna esse movimento uma instância política ainda mais significativa, pois a participação de mulheres (literária e politicamente) contribui para uma ressignificação das identidades das mesmas, as quais são, geralmente, estigmatizadas como mulher e periférica apenas. Logo, essas escritoras, em suas produções e declamações, questionam a autoridade e o privilégio patriarcal nos âmbitos público e privado, assim como no campo literário. Também é ressaltado por Tennina que o fato de os saraus acontecerem em bares, ambiente historicamente inerente aos homens, e não às mulheres, descontrói ainda mais a questão dos espaços que seriam legítimos a elas, segundo uma perspectiva patriarcal e hegemônica, além de desestabilizar as noções conservadoras de sexo/gênero e redefinindo os

papéis atribuídos a elas [mulheres], como a dedicação prioritária à vida doméstica e aos familiares, [os quais] colaboraram para que a domesticidade feminina fosse vista como algo natural e distintivo, mas também como um valor a partir do qual outros comportamentos seriam caracterizados como desvios" (Miguel e Biroli, 2014: 32).

Além disso, a participação efetiva das mulheres nos saraus da periferia reforça a ideia de sujeito social defendido por Teresa de Lauretis, em que este deve ser "múltiplo em vez de único, e contraditório em vez de simplesmente dividido" (Lauretis, 1994: 208), tendo em vista que, por meio destas mulheres, tem-se acesso às várias identidades que elas possuem. Suas produções, conforme a análise feita, deixa claro que a produção literária feminina pode consumar-se independentemente do tema a ser abordado, descontruindo, dessa forma, o preceito de que as mulheres deveriam se dedicar apenas a temáticas amenas e/ou confessionais.

No quarto, e último, capítulo, A figura do escritor, entre a proposta coletiva e um projeto individual, a autora demonstra que a produção da literatura marginal da periferia não é composta apenas de poesia, pois "além de uma vasta produção vinculada aos saraus de poesia como parte de uma proposta coletiva de autoafirmação, é composta também por outra série de produções (formada predominantemente por romances), que aparecem ligadas, ao mesmo tempo, à preocupação com a legitimação e o posicionamento dentro do campo literário estabelecido" (Tennina, 2017: 226), isto é, há autores cuja pretensão é projetar sua imagem individual, conquistando leitores para além dos circuitos periféricos.

A fim de ilustrar tal afirmação, a teórica traz os estudos dos casos de Alexandre Buzo e Ferréz, os quais são pioneiros desse grupo de escritores marginais de periferia que buscam uma projeção além do seu 
território. A partir da análise da produção literária destes, feita pela autora, é interessante observar que tanto Buzo quanto Ferréz constroem um duplo perfil, abordando as questões já mencionadas no parágrafo anterior sobre o coletivo e o individual, todavia eles o fazem de maneiras distintas, já que não utilizam as mesmas estratégias e recursos. A legitimação desempenha papel fundamental nesse processo, por isso Tennina discute detidamente sobre os agentes literários que envolvem as publicações destes autores (editoras, críticos literários, trabalhos acadêmicos...), os quais endossam suas narrativas e as inclui no campo literário.

A trajetória de Ferréz (e seu intuito de participar do cânone literário) é bastante peculiar, e seu discurso, assim como sua obra, é por vezes ambíguo. Ferréz declarou certa vez, em entrevista concedida à revista Caros Amigos: "Eu escrevo para a periferia, mano, quem lê de fora é bastardo" (Ferréz, 2009: p. 15), ou seja, nesta fala ele se mantém e se restringe ao sistema literário marginal da periferia. Em outro momento, ele contradiz a afirmativa anterior: "Ainda que escreva prioritariamente para minha comunidade, não quero minha literatura no gueto. Quero entrar para o cânone, para a história da literatura como qualquer um dos escritores novos contemporâneos" (Ferréz apud Hollanda, 2008). Entretanto, independentemente do seu posicionamento, o autor conseguiu a legitimação que almejava pelas instâncias de reconhecimento do campo. E isso se deu não somente pela temática de seus textos, bem como pela consistência destes, de acordo com a análise da pesquisadora. Dessa forma, Ferréz ultrapassa a fronteira entre a "cidade marginal" e a "cidade oficial" esses grupos marginalizados, que habitualmente são representados por outrem, passam a se autorrepresentarem, isto é, são sujeitos de sua própria fala, nos evidenciando uma perspectiva interna e legítima da periferia. Por conseguinte, é necessário que a cultura e, consequentemente, a arte marginal seja respeitada. As diferenças não devem ser usadas como aporte/ argumento para discriminações e preconceitos e que, desse modo, essas vozes possam não apenas falar, como também serem ouvidas.
Por fim, ressalto que a autora consegue discutir neste livro várias questões sobre a literatura marginal periférica que não foram abordadas (ou não foram abordadas com tanta propriedade) pela bibliografia sobre o tema existente até então. Além disso, as discussões trazidas por Tennina constata que a literatura marginal periférica vem se mostrando como uma potência política e estética de renovação e ruptura de padrões, bem como fomentando o debate sobre essa literatura, ainda considerada por muitos como menor, contribuindo, dessa forma, para a construção de um novo olhar sobre a mesma. Sua obra também oferece visibilidade aos textos que ainda não conseguiram se deslocar geograficamente e "invadir" o espaço do campo literário nacional, demonstrando que diversas questões relevantes podem/devem ser representadas por uma perspectiva interna dos grupos marginalizados e possibilitando, assim, uma democratização da literatura. A periferia, a qual é rotulada como um lugar de onde provém apenas violência, tem revelado ser um lugar de onde provém cultura, além de delinear, segundo Tennina, uma nova cartografia paulista, um verdadeiro mapa afetivo do circuito de saraus.

\section{Bibliografia}

»Candido, A. (1997). Formação da literatura brasileira. Belo Horizonte: Itatiaia, v.1 e 2.

» Candido, A. (2011). O direito à literatura. En Candido, Antonio, Vários escritos. Rio de Janeiro: Ouro sobre Azul.

» Biroli, F. y L. F. Miguel. (2014). Feminismo e política. São Paulo: Boitempo.

'Bourdieu, P. (2014). A dominação masculina. São Paulo: BestBolso.

» Dalcastagnè, R. (2007). A auto-representação de grupos marginalizados: tensões e estratégias no narrativo contemporâneo. In Letras de Hoje. Porto Alegre, v. 42, n. 4, pp 18-31, dezembro. 
» Dalcastagnè, R. (2012). Literatura brasileira contemporânea: um território contestado. Rio de Janeiro: Editora Horizonte.

» Ferrez. (2009). A periferia de São Paulo pode explodir a qualquer momento. En Caros Amigos, São Paulo, n. 151, pp. 12-17.

» Hall, S. (2003). A identidade cultural na pós-modernidade. Rio de Janeiro: DP\&A.

»Hollanda, Heloísa Buarque de. (2018). Intelectuais x marginais, 2008. Disponível em http://www.literal.com.br. Acesso em 17 jun.

» Lauretis, Teresa de. (1994). "A tecnologia do gênero", En Hollanda, Heloísa Buarque de (ed.), Tendências e impasses: o feminismo como crítica da cultura. Rio de Janeiro: Rocco.
》Nascimento, Érica Peçanha do. (2009). Vozes marginais na literatura. Rio de Janeiro: Aeroplano.

»Schollhammer, K. E. (2000). Os cenários urbanos da violência na literatura brasileira. En Pereira, Carlos Alberto Messeder (ed), Linguagem da violência. Rio de Janeiro: Roxo.

»Showalter, E. (1989). Speaking of gender. New York and London: Routledge.

» Tennina, L. et al. (2006). Polifonias marginais. Rio de Janeiro: Aeroplano.

»Tennina, L. et al. (2017). Cuidado com os poetas! Literatura e periferia da cidade de São Paulo. Porto Alegre: Zouk. 